\title{
IMAGING CONNOTATION OF EMOJIS ON COMMUNICATION AND MESSAGE PERCEPTION
}

\author{
Aditya Gautam \\ Student \\ IIMC NER Campus
}

\author{
Dr.C.Lalmuansangkimi \\ Assistant Professor \\ IIMC NER Campus
}

\begin{abstract}
As languages develop they undergo many changes which sometimes persist and sometimes do not. Keeping in mind the scope of these changes and the time they take, emojis are a still a mere blip in the field of communication and this situation is further compounded by the fact that emojis are essentially a part of technology, which is overtaken by better technology almost every day in today's world. Whether the increasing shift in favor of textual conversation, and consequently in use of emojis, is depreciative to human communication or not, is perhaps a question of philosophy; this empirical research aims to dissect and analyze the ways in which emojis pervade all our conversations, the way they change the perception of a message and the psychological reasons, and the explanations, behind such changes.

The study posited that the use of emojis has not really been adopted by older generations, when compared with young adults. The inference revealed the intent of people behind adding emojis to their text is the intent to clarify or accentuate a message. Intentions, however, do not necessarily translate into effect which is clear from further data. Emojis thus do not clarify or accentuate the message in case of all emotions, which is understandable because humans do not react the same way to every emotion. The study prove that the emojis are used as a whole in the capacity of non-verbal cues, and the lack of them is equated with the lack of their counterparts, thus portraying a person who doesn't use emojis as a person who does not betray any facial expressions, body language signs and other affectations that help in message perception.
\end{abstract}

Keywords- Emoji, Online, Disinhibition, Perception, Animoji, Invisibility

\section{INTRODUCTION}

\section{- Party today. Yay!! \& $3 x$}

\section{- (iiㄹ That was a brave act of loyalty}

- Goodnight

These are three common examples of text messages that may be generalized to many users of popular messaging and social-media applications. The point, to be made with the help of these examples, is the reliance on emojis to convey tones, emotions and accentuations.

The first emoji was created by Shigetaka Kurita in 1999. He felt the need to do so because the mobile internet system he was working with restricted the number of characters in an e-mail to 250. In Kurita's own words, "We thought emoji would be a quick and easy way for them to communicate. Plus using only words in such a short message could lead to misunderstandings ... It's difficult to express yourself properly in so few characters." (McCurry, 2016) ${ }^{1}$

That was 1999, and our communications were mostly independent on glass screens; jump to present day and emojis are everywhere. An idea might cross one's mind, at this point of time, to scoff at the previous sentence. Therefore, consider this: a man called Fred Benenson translated Moby Dick into a book he calls Emoji Dick, every word of Moby Dick translated into emojis with the help of a computer bot. The book was included by US Library of Congress for their archive (Hollander, 2013). ${ }^{2}$ In a further attempt, the first ever Emoji Art Show was held in New York in 2013 (Dunne, 2013). ${ }^{3}$ The Oxford Dictionary also, in 2015, chose 'the laughing face' emoji as its word of the year (oxforddictionaries.com, 2015). ${ }^{4}$ In 2017, one of the most hyped-about features of the new phone by Apple Inc. was a more interactive type of emoji which they have named 'animoji' (support.apple.com, 2017). These examples, while bizarre, prove the extent to which emojis and their use has pervaded popular culture.

If you reflect a little, you will realize how many times you decide in favor of a text message as opposed to a call, and how many of those text messages are sans-emojis. It is the reality

\footnotetext{
${ }^{1}$ An interview with emojis creator Shigetaka Kurita by Justin McCurry (https://www.theguardian. com/technology /2016/oct/27/emoji-inventor-shigetaka-kurita-moma-new-york-text) ${ }^{2}$ https://www.bustle.com/articles/9208-emoji-dick-moby-dicktranslated-into-emoji-icons-this-exists ${ }^{3} \mathrm{http} / / / \mathrm{www}$. dazeddigital.com/artsandculture/article/18150/1/theworlds-first-emoji-art-show-opens-today ${ }^{4} \mathrm{https} / / / \mathrm{en}$. oxforddictionaries.com/word-of-the-year/word-of-theyear-2015
} 
that our days now start with checking WhatsApp for new messages, they end with a sweet goodnight message followed by a 'kiss' emoji, and all the time in the background of this texting we keep devising better ways--not always consciously-to put across (or conceal, when needed) the intentions and connotations of our text messages.

Whether this increasing shift in favor of textual conversation, and consequently in use of emojis, is depreciative to human communication or not, is perhaps a question of philosophy; all this research aims is to dissect and analyze the ways in which the cute little yellow emojis pervade all our conversations, the way they change the perception of a message and the psychological reasons, and the explanations, behind such changes.

\section{CONCEPTUALIZATION OF EMOJIS}

As languages develop they undergo many changes: words are added and removed, grammatical changes come and go out of fashion, individuals have their own effects, which sometimes persist and sometimes do not. All of this evolution, or devolution, happens over millennia and is analyzed over decades. Keeping in mind the scope of these changes and the time they take, emojis are still a mere blip in the field of communication and this situation is further compounded by the fact that emojis are essentially a part of technology, which is overtaken by better technology almost every day in today's world.

Case in point, 'animojis', which were launched by Apple Inc. in 2017 are a whole new type of communication tools. Also, if you think they are just a marketing gimmick consider the fact that Tim Cook, C.E.O of Apple Inc., addressed the graduating students at Duke University, his alma mater via animojis (Petrov, 2018). ${ }^{5}$ Therefore, all research on emojis must be done and read while keeping in mind their young age and constant evolution.

According to common perception, emojis are the substitute of nonverbal cues in textual communication. As such, other contexts of research may inform their expected impacts. In print advertising - another medium where textual messages are emphasized or accompanied by pictorial componentspeople were found to rate advertisements with a pictorial or graphic component higher than those without; ads with a textual/ graphic combination are more effective than those with a textual message alone (Childers \& Houston, 1984; Shepard, 1967) and research has also shown that imagery has a positive impact on learning and retention (Lutz \& Lutz, 1977). The use of visual cues along with text has also been shown to produce a more positive attitude than text alone ( $A$. A. Mitchell, 1986). This certainly suggests that as far as the degree of perception is considered, emojis may have a positive effect, however, whether they effect the perception of the

${ }^{5}$ https://www.phonearena.com/news/Watch-Tim-Cook-try-Animojifor-a-Duke-commencement-ceremony_id101811 message's meaning is another question altogether. A comprehensive review of nonverbal communication literature by Burgoon et al. (1996) $)^{6}$ concluded that nonverbal behaviors predominates the effects of language content in most conditions. Reviewing the "channel reliance" findings, the authors concluded that "if verbal and nonverbal cues were relatively equal in strength when judged separately, the nonverbal cues dominated verbal ones when they were paired together" (Burgoon et al. 1996). These findings were also dependent on the subject matter that the participants of the study were asked to observe: for factual information verbal cues were given more importance by the participants, whereas 'emotive, relational or attributional' outcomes nonverbal cues took precedence.

To get an idea of the way in which emojis can change the entire context of a text message, this image sourced from ivyinvestments.com is very helpful:
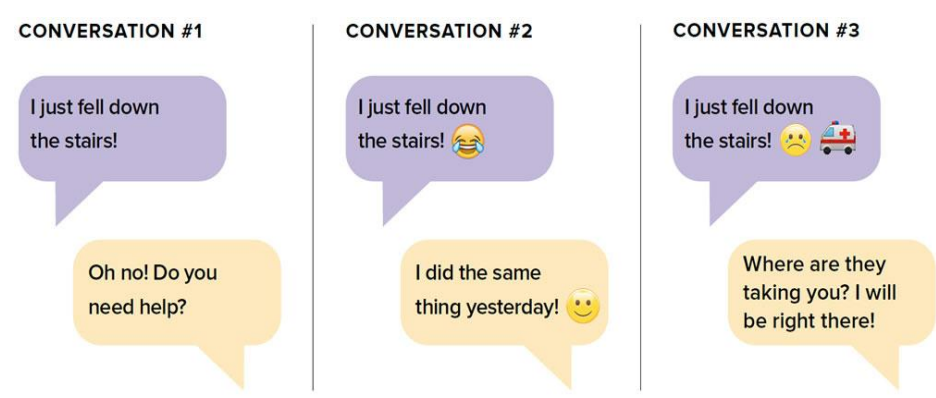

Fig. 1 Graphic courtesy of ivyinvestments.com

In the first conversation, with no emojis to aid the text message, the context remains entirely unclear. In the second conversation the addition of a single emoji to the text message makes it clear that the context is a humorous one, in contrast to the third conversation where it is immediately clear, by the courtesy of two emojis, that it is a serious matter and the sender has probably being hospitalized.

The accentuation of messages by the use of emojis has also been of particular interest to researchers. A study of students at a secondary school and their use of emoticons suggested that they can help reinforce a message's meaning. Researchers found that emoticons, when used in conjunction with a written message, can help to increase the "intensity" of its intended meaning (Derks et al, 2007).

Not everyone, however, is all praises for the effect of emojis in communication. Alice Robb writes that "it's no surprise that millennials have embraced emoji and their pixelated cousins, emoticons" $(R o b b, 2014) .^{7}$ Also, even

\footnotetext{
${ }^{6}$ Burgoon, et al. (1996). Nonverbal communication: The unspoken dialogue (2nd ed.). New York: McGraw-Hill.

${ }^{7}$ An article "Are Emoji Taking the Emotion Out of Our

Communication?" written by Alice Robb for newrepublic.com
} 
though new emojis are been developed and added to messaging apps on a regular basis, their number is not nearly high enough yet to cover the wide range of human emotions. This can lead to restriction on the emotions that we are able to express, and an omission of many subtleties associated with them. For example, Facebook offers its users the chance to 'react' via one of the only six possible options provided to them, thus effectively restricting the freedom of these users' reaction capability.

Ambiguous, superficial, and cute, they're perfectly suited to a generation that sends Hallmark e-cards ironically, circulates step-by-step guides to "being deep," and dismisses "deep meaningful conversations" as "DMC's" (Robb, 2014). Good or bad, the extent to which we use emojis cannot be ignored. In 2012, a team of psychologists at Rice University gave 21 college students-eleven male, ten female-free iPhones they could monitor, without telling their subjects the purpose of the experiment. Over the course of the next six months, the researchers collected and analyzed about 124,000 text messages sent by the group. Everyone involved in the study sent an emoticon at least once, though most people used them infrequently: Just 4 percent of all text messages contained an emoticon-and these were twice as likely to be sent by a woman $($ Robb , 2014). This suggests that there is also a lot of variation, in emoji, among different age groups and genders.

A study conducted to analyze this variation based on gender amongst the users of Facebook found out that women tended to feel jealousy as a result of online communications, however, men tended to feel jealous as a result of other user's messages, when emojis were present (Hudson et al., 2015).

\section{CRITICAL APPRAISAL OF THE THEORETICAL FRAMEWORK}

\section{A. Emojis and the Theory of Online Disinhibition -}

The term 'online disinhibition' had been in use for a while when Suler organized the loose concepts and published his article called 'The Online Disinhibition Effect' in 2004. Everyday users on the Internet-as well as clinicians and researchers-have noted how people say and do things in cyberspace that they wouldn't ordinarily say and do in the face-to-face world. They loosen up, feel less restrained, and express themselves more openly. So pervasive is the phenomenon that a term has surfaced for it: the online disinhibition effect (Suler, 2004).

There are six psychological factors which were identified by Suler as being the primary causes of online disinhibition. These six factors are:
1. Dissociative anonymity
2. Invisibility

(2014). Link available at https://mashable.com/2014/07/09/emojilinguists-communication/\#yFNfGPN9Nqq3
3. Asynchronicity

4. Solipsistic introjection

5. Dissociative imagination, and

6. Minimization of status and authority

In relation to the effect of emojis on communication in general, and message perception in particular, the concept and theory of online disinhibition is important because it describes and explains how the way people communicate online is different from the way they communicate in real life.

For instance, when Suler describes the factor of invisibility in his theory, he says that, "In many online environments, especially those that are text-driven, people cannot see each other. When people visit web sites, message boards, and even some chat rooms, other people may not even know they are present at all - with the possible exception of web masters and other users who have access to software tools that can detect traffic through the environment, assuming they have the inclination to keep an eye on an individual person, who is one of maybe hundreds or thousands of users."

The perception of invisibility gives people the courage to do things they wouldn't otherwise do in real life and often go overboard. "Although this power to be concealed overlaps with anonymity-because anonymity is the concealment of identity-there are some important differences. In the text communication of e-mail, chat, instant messaging, and blogs, people may know a great deal about each other's identities and lives. However, they still cannot see or hear each other," Suler postulates. He further added, "Even with everyone's identity known, the opportunity to be physically invisible amplifies the disinhibition effect. People don't have to worry about how they look or sound when they type a message. They don't have to worry about how others look or sound in response to what they say. Seeing a frown, a shaking head, a sigh, a bored expression, and many other subtle and not so subtle signs of disapproval or indifference can inhibit what people are willing to express."

This inability to 'see or hear each other', this absence of frowns shaking heads, sighs, bored expressions et all creates a vacuum in communication for all the parties involved in it, and emojis are the tool at hand that move in to fill this vacuum. Take the case of admitting love to a partner by saying the three magical words. In a real life scenario, the words alone are enough, even more than enough, and carry a lot of weight because the implications they carry, however they are supplemented in such a situation by facial expressions, smiles or simply by subtle phonetic emphasis, which are all of them absent in the case of textual communication. The theory of online disinhibition is helpful in explaining this scenario when applied to textual communication by pointing out how it might be natural, or even needed, there to bombard the 'i-love-you's with kiss-emojis. Social inhibition might make it weird to do that every time for the senders in real life, but online it is very much fine, similarly the recipients too might consider the message more sincere with the addition of emojis, because they are trying to make up for all the missing non-verbal cues. 
Another factor defined by Suler, relevant to this research, is that of solipsistic introjection. Absent face-to-face cues combined with text communication can alter self-boundaries. People may feel that their mind has merged with the mind of the online companion. Reading another person's message might be experienced as a voice within one's head, as if that person's psychological presence and influence have been assimilated or introjected into one's psyche (Suler, 2004).

Therefore, textual communication may feel more like talking to oneself than like talking to another individual. In such a situation it is interesting to see the need behind the use of emojis, because it is like over-explaining a sentence in one's own mind. In his research, Suler extrapolates this further: Online text communication can evolve into an introjected psychological tapestry in which a person's mind weaves these fantasy role plays, usually unconsciously and with considerable disinhibition. Cyberspace may become a stage, and we are merely players. When reading another's message, one might also "hear" the online companion's voice using one's own voice. People may subvocalize as they read, thereby projecting the sound of their voice into the other person's text. This conversation may be experienced unconsciously as talking to/with oneself, which encourages disinhibition because talking with oneself feels safer than talking with others. For some people, talking with oneself may feel like confronting oneself, which may unleash many powerful psychological issues.

Another online disinhibition related study placed value on the unique features of computer-mediated communication (CMC; i.e., reduced nonverbal cues and enhanced message control) was associated with greater feelings of disinhibition, which in turn predicted higher levels of preference for online social interactions (POSI). Negative outcomes due to Internet use are associated with POSI (Silvia et al., 2015).

In the light of these points, it is apparent that online disinhibition has a part to play in the way we use emojis for our communication needs and also the way we perceive them. It is easier to laugh, be angry, love, or in general 'emote' when doing it through minuscule images wrapped inside text, than it is to do so in real life. The role of online disinhibition theory in the studying how emojis effect communication, therefore, is paramount in understanding the need people feel of using them and the different scenarios where emojis may accentuate, trivialize, or clarify the intent of a message.

\section{EXPERIMENT AND RESULT}

The survey regarding the effects of emojis on communication was conducted online over a sample consisting almost equally of men and women. The participants were all internet users, considering the relevant audience of emojis. Their ages varied from 16 to 45 and 62 percent of them were students, compared to 38 percent professionals.

The questionnaire administered to the participants in this survey aimed at bringing out the extent of need, perception and use of emojis in communication, so as to gauge the effect of them on it, and especially on message perception depending on the tone of the original text message, the extent of it, and the emoji(s) added to it. Towards this endeavor the participants were also encouraged to elaborate on their responses in relevant questions, and also in one case to answer from the perspective of other people. The analysis of all the questions and of the participants' responses to them is presented here, followed by the inferences drawn from them.

To find out the extent to which textual conversation is preferred over calls in this age of smartphones, the participants were asked whether they would prefer sending a text over calling someone in two different type of scenarios: namely, personal conversations and professional conversations. The terms 'personal' and 'professional' were deliberately included with their ambiguity so as to let the participants apply their own definition of what constitutes personal and professional for each of them. In the first case, that is the case of personal conversations 38 percent of the people said they would prefer the textual form of communication, and for professional conversations 46 percent people said so. After taking the average of these two figures, it is appears that 42 percent of the people will prefer textual conversation as their method of communication over making a phone call. To get an idea of how much people use emojis in these textual conversations, the participants were asked to give an estimate of the number of messages out of their last 15 messages in which they had used emojis. A statistical analysis of this data points to the median figure of _ emojis used per person in their last 15 messages.

Narrowing down the line of inquiry, the participants were then asked if they also use emojis in their impersonal conversations, for example, while talking to a teacher or a boss. 45 percent of the participants would not use emojis in such a communication. When asked to elaborate on why they would not do so, most of the participants responded that emojis are unsuitable for professional conversations and only to be used while talking to the people with whom one is on friendly or personal terms. To quote some of them verbatim: 'Not Professional enough', 'I think it is improper and the way our parents and friends know us, the boss and teacher wouldn't. Our relation to them is purely professional' and 'Because one don't have need to show expressions while doing conversation with boss, in an impersonal conversation words have more value...'. A few people also touched on the ambiguous nature of emojis, and thus the perils of using them in such conversations. Responses like, 'There are no standard semantics for an emoji. People might perceived different meanings out of it. The message you intend to deliver might alter because of this confusion', 'I like to keep discussions straight and to the point.', and 'Emoji's can be misinterpreted. Too many choices.' make clear the fact that users are indeed conscious of the fact that the same emoji can be interpreted in a number of different ways. 


\section{International Journal of Engineering Applied Sciences and Technology, 2019 \\ Vol. 3, Issue 12, ISSN No. 2455-2143, Pages 50-58 \\ Published Online April 2019 in IJEAST (http://www.ijeast.com)}

Majority of the participants ( 80 percent) also held with the belief that older people are less likely to use emojis. The age group of the people involved in the survey might have some bearing upon this outcome, considering that younger generations are of course inclined towards considering their elders less savvy than themselves, which is also true to some extent. More, interesting analysis than that of the majority opinion, however, is that of the people who responded otherwise. For instance, one response showed something that is easily observable in day to day life about the elderly who have recently adoped messaging apps: 'Adults tend to over use it!' Another question put to the participants asked them what, in their opinion, is the effect that emojis have upon the message they accompany. The participants were given four broad options to choose from, namely, accentuation, trivialization, clarification, or no effect at all. The analysis of the responses is as follows:

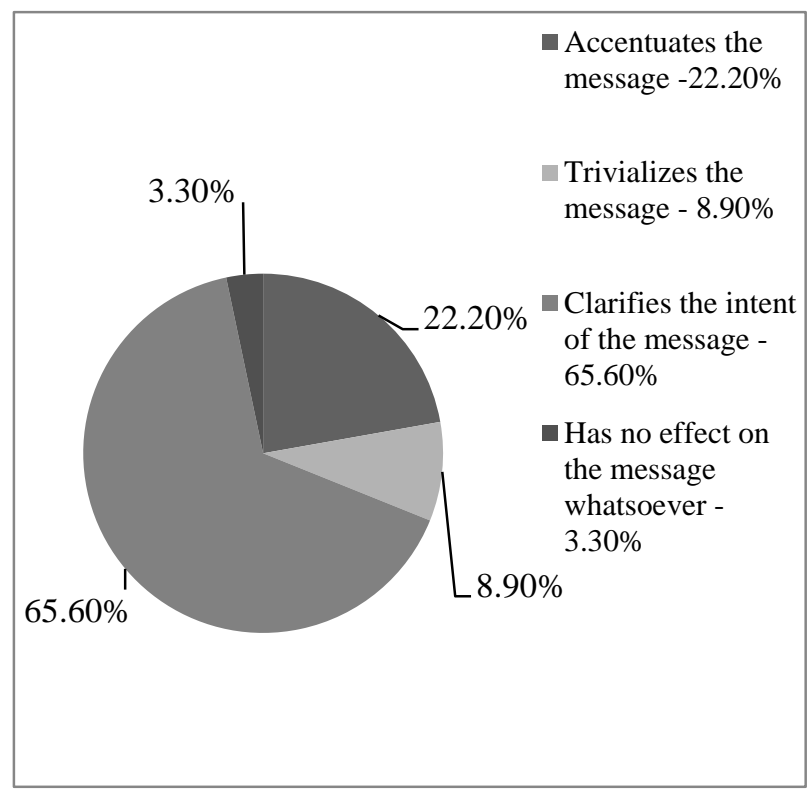

Fig.2 Effects of emojis on messages

As can be seen from the above chart, the majority of participants hold that addition of emojis clarifies the intent of a message, followed by those who agree with accentuation and trivialization respectively. Only a very small number of participants responded with the answer that emojis have no effect on the message whatsoever.

To measure the way that people respond to different types of emojis in various conditions and different emotions, i.e. anger, humor and love. The participants were asked to choose which messages were most effective for them, and were provided with four options ranging from plain text without emoji, combinations of emoji to just emojis without text.

In case of anger the participants were provided with a hypothetical scenario in which they have been teasing a friend since some time and the friend replies with one of the four provided options, the participants were asked which response would convince them that the friend was really angry.

The options provided to them were:

Don't talk to me anymore. **no emoji**

Option 2:

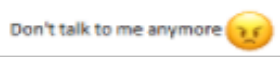

Option 3:

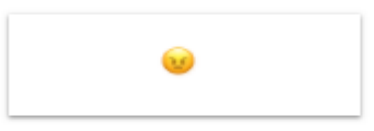

Option 4:

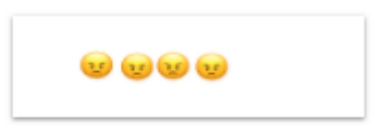

Fig.3 Depiction of Anger

The majority ( 52 percent) of the participants chose the first option i.e. plain text without an emoji.

In case of humor, the participants were asked to imagine that they have sent out a joke to some friends and receive the options as replies. They were asked to choose the option that would convince them that the recipient found the joke funny. The options provided to the participants were: 
Hahaha $\quad$ **no emoji**

Option 2

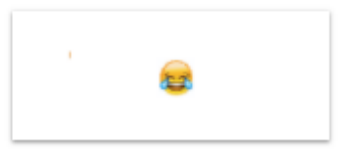

Option 3

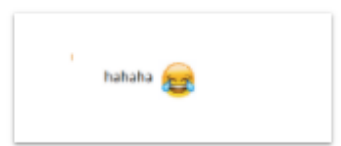

Option 4

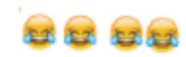

Fig.4 Depiction of Humor

The analysis of the responses is as depicted by the following chart:

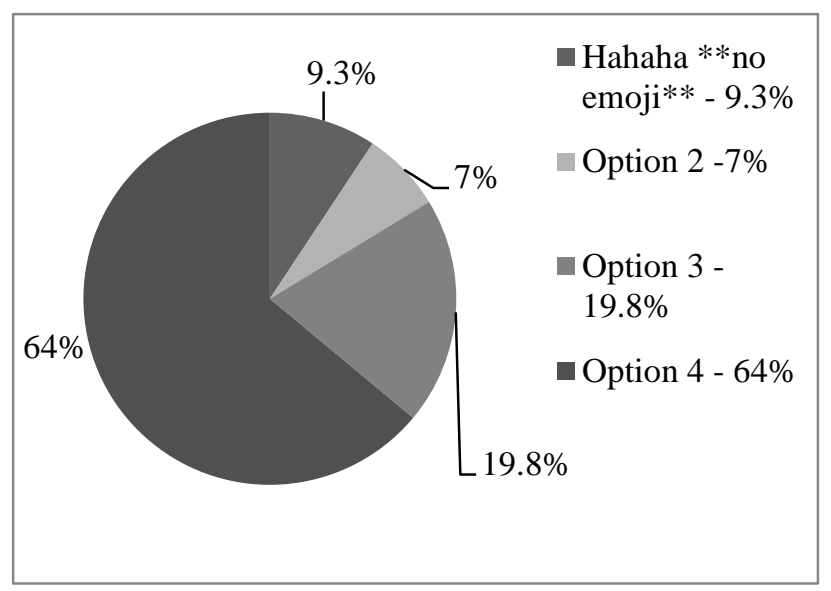

Fig. 5 Chart representation of Depiction of Humor

In the case of humor, therefore, the majority of participants has sided with the option that had only emojis, and an excess at that, and no text. The response is in direct contrast to that in the previous situation.

In case of love, the 'admission of love' i.e. the phrase 'I love you' was chosen as a benchmark and the participants were provided with two options: first, the words alone, and second the words accompanied by a kiss emoji, and they were asked in which case would they consider the admission more sincere. The options, as presented to the participants

I love you. $\quad$ **no emojii*

\section{Option 2}

I love you

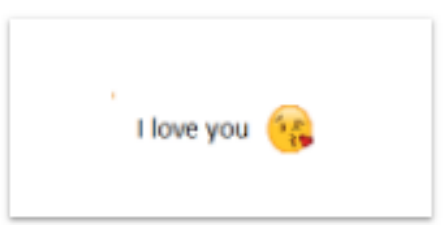

Fig.6 Confession of feelings

The analysis of the responses is a tale of middle ground, with the participants almost equally divided between the two options, but slightly favoring the plain text without any emojis.

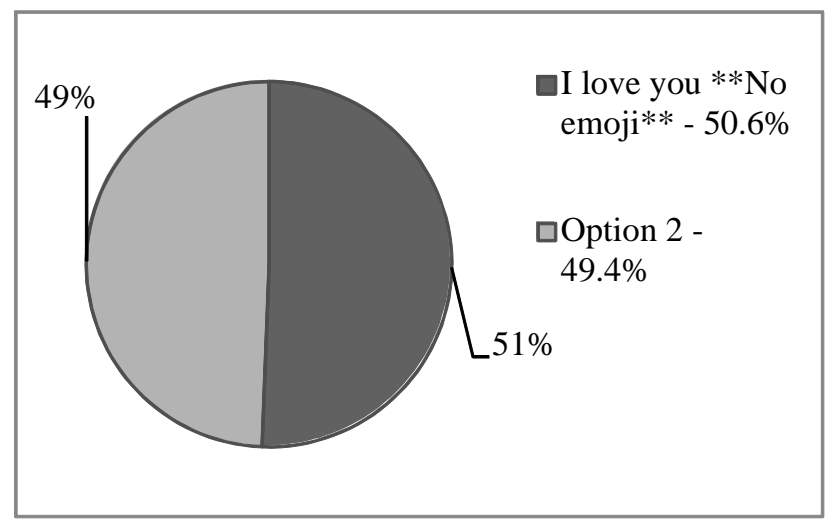

Fig. 7 Chart representation of Confession of feelings

The last two questions were designed to check the effect of emojis on the perception of someone's over-all personality. This was achieved by presenting a hypothetical person who uses no emojis while conversing with the participant, and asking the participant what inferences would this quirk cause to be drawn about such a person. Keeping in mind that the participants may not be too eager to admit that they'll draw any negative inferences, the question was divided into two parts:

a) What inferences would the participant draw about such a person? 
b) What inferences does the participant think other people might draw about such a person?

The options for inferences provide to the participants were:

\section{The person is socially awkward}

\section{The person is lonely.}

The person is sincere.

The person is not friendly.

No inferences: he/she is just a regular person

The analysis of responses for the two questions is as follows. For the participants own inferences:

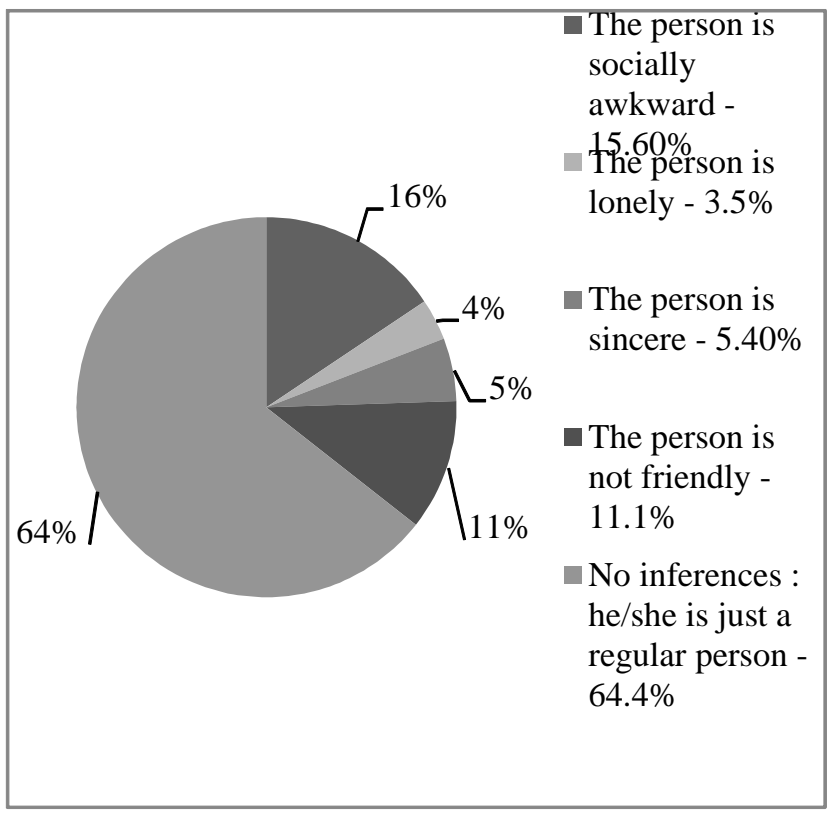

Fig.8 Participants' inferences

So, while talking about themselves the wide majority of participants said that they would make no judgement about a person based on the fact that he/she does not use any emojis in his/her conversations.

The analysis for the second question, about what they think other people would infer reveals a different chart.

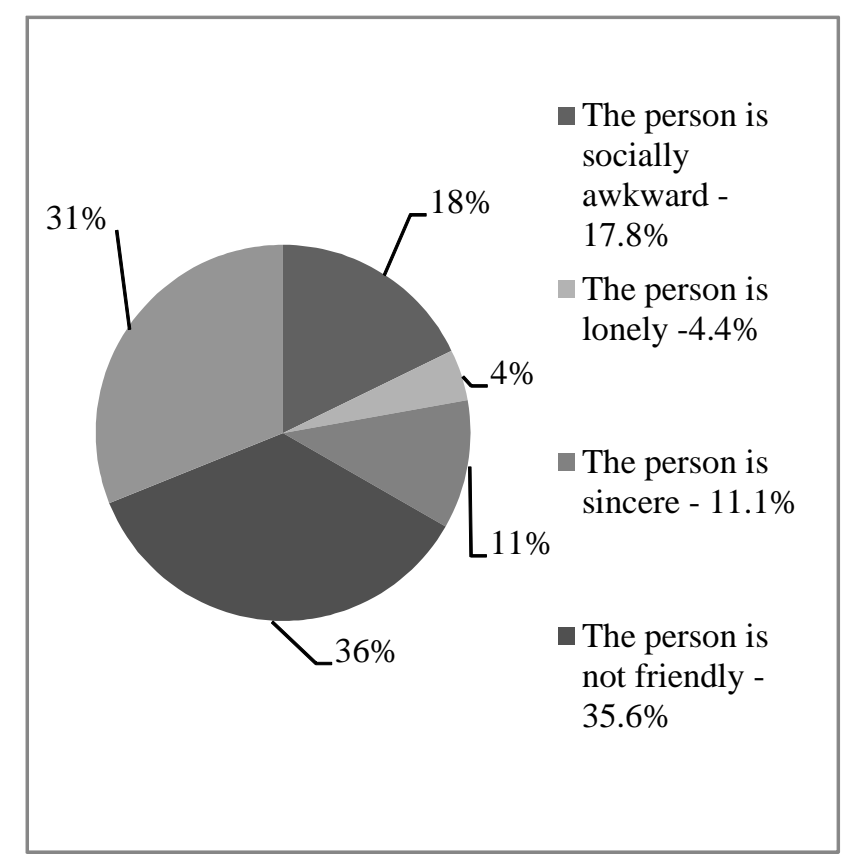

Fig.9 what participants think other people would infer

\section{IV.CONCLUSION}

The analysis provided allows inferences to be drawn from the data collected in this study, some of those inferences based on the responses that participants gave and a few based on the responses which they deliberately chose not give.

The two questions to measure the extent by which textual conversation is now preferred over calls, or other methods of communication, in the scenarios of personal and professional conversations, show by the analysis of their responses that while the percentage of people who would prefer a call in both the scenarios is higher, it is not higher by a very large margin (by $8 \%$ in case of professional conversations and by $24 \%$ for personal conversations). Considering the fact that most of the popular messaging apps like WhatsApp, or Facebook Messenger, have been available to the people for less than a decade and voice calls have been around for a much, much longer time, these statistics prove that textual communication is soon catching up, even though it is restricted by many factors like internet availability and lack of use among older generations. The preference to textual conversation is a premise to this research because textual conversations are essentially the playground of emojis, and therefore relevant to any discussion about them.

About the use of emojis themselves, almost $80 \%$ percent of the people agreed that the use of emojis has not really been adopted by older generations, when compared with young adults. This result, in fact, agrees with the study conducted by 
Franklin Krohn of the State University of New York in Fredonia. Krohn cautioned against sending emoticons (the precursor to emojis) to people of the Baby Boomer generation, or previous generations, in a work context (Krohn, 2004). However, focusing only on the 'work context' data reveals that $55 \%$ of the participants are indeed comfortable with using emojis in impersonal conversation with their boss or teacher, which tells us how deeply the emojis have pervaded our lives since 2004, when Krohn conducted his study.

These first few questions focus more on how much people use textual conversations and emojis in those conversations, and the inferences from the answers reveal their importance. Then, we move on to the effects of these emojis on the intent of the message, i.e. on message perception. When asked directly as to what do they think is the effect of an emoji when added to the message, a two-third majority of the participants chose to respond that emojis clarify the intent of a message, followed by $22 \%$ people who said that emojis accentuate the meaning of the message. The inference drawn from this answer is the intent of people behind adding emojis to their text: the intent to clarify or accentuate a message. Intentions, however, do not necessarily translate into effect, and that is clear from further data. When presented with three different emotional situations, anger, humor and love, people deviated from the effect of emojis which they had proclaimed in the previous response, i.e. clarification or accentuation. In case of anger, a simple text message without any emojis emerged as being perceived by the participants to be the most effective conveyor of anger, compared to messages with a mixed text and emojis, or even standalone emojis. Similar results came up in the case of love, where admission of love was perceived as being more sincere by the participants when it was unaccompanied by a kissemoji, though in this case the difference between the number of people who chose either option was less than in the case of 'anger-scenario'. It was in the case of laughter that the participants did favor emojis, and in that case they favored the option that consisted solely of emojis, with no text at all.

Emojis thus do not clarify or accentuate the message in case of all emotions, which is understandable because humans do not react the same way to every emotion. In case of serious situations like a participant's friend being angry, or a lover admitting his love, plain text is perceived to be more effective in conveying the intent of the message. The addition of emojis in such cases merely introduces insincerity in a situation which has no need for it, for instance, a message that says 'don't talk to me anymore' followed by an angry-red-face emoji make it appear as if the sender is only playfully angry or is feigning anger, thus trivializing the message. Similar, in an admission of love, plain text reserves a sincerity that cannot be afforded by a kiss-emoji.

Yet, emojis work in the case of humor, proving that in an already insincere or playful situation, they are a tool which can be used to accentuate the message perception and even to clarify the intent of the message.

The last two questions which were posed to the participants also dealt with the effect of emojis, albeit on a broader scale of how the use, or no use in this particular case, of emojis may cause inferences to be drawn about an individual's personality. To this end, when the participants were asked what conclusions would they draw about a person who talks to them via texts, but never uses any emojis. For their own personal selves the participants replied by a wide majority that they would draw no inferences about the person based on his lack of emoji-use, however, when asked what inferences they think other people might draw about such a person, the favored answer was that the 'person is not friendly'. It is safe to assume that this latter option is the inference that the participants would also draw, as a subconscious feeling perhaps, if not as an abject judgement.

These responses thus prove that the emojis are used as a whole in the capacity of non-verbal cues, and the lack of them is equated with the lack of their counterparts, thus portraying a person who doesn't use emojis as a person who does not betray any facial expressions, body language signs and other affectations that help in message perception. Thus, leading to his/her judgement as an unfriendly person. The use of emojis therefore, while not clarifying, accentuating, or trivializing the message in every case for every emotion, still is a major force in the perception of the entire conversation as being friendly or unfriendly, professional or unprofessional, personal or impersonal, and sincere or insincere.

\section{REFERENCE}

[1] Burgoon, J. K., Buller, D. B., \& Woodall, W. G. (1996) "Nonverbal communication: The unspoken dialogue"(2nd ed.), New York: McGraw-Hill.

[2] Childers. T. and M. Houston (1984) "Conditions for a Picture Superiority Effect on Consumer Memory", Journal of Consumer Research. 11 (Sept). Pg 643-655.

[3] Derks,D.,Bos,A. E. R.,\& von Grumbkow,J. (2007) "Emoticons and social interaction on the Internet:Theimportance of social context", Published in Computers in Human Behavior, 2007.

[4] Dunne, Eleanor (2013), "The world's first emoji art show opens today" retrieved from (http://www.dazeddigital. com/artsandculture/article/18150/1/the-worlds-first-emoji -art-show-opens-today

[5] Eco, Umberto (1977) "A Theory of Semiotics", Published by Macmillan.

[6] Hollander, Jenny (2013), "Emoji Dick: Moby Dick, Translated Into Emoji Icons. This Exists" retrieved from https://www.bustle.com/articles/9208-emoji-dick-mobydick-translated-into-emoji-icons-this-exists 
[7] "How emojis enrich nonverbal communication" retrieved from https://www.ivyinvestments.com/content/howemojis-enrich-nonverbal-communication (2017)

[8] https://support.apple.com/en-in/HT208190

[9] Hudson et al., (2015) "Examining How Gender and Emoticons Influence Facebook Jealousy", Cyberpsychology, Behavior and Social Networking, Volume 18 (2):87-92

[10] Krohn, B., Franklin (2004) "A Generational Approach to Using Emoticons as Nonverbal Communication", Journal of Technical Writing and Communication. Volume: 34 issue: 4, page(s): 321-328 Issue published: October 1, 2004

[11] Lutz, K. A., \& Lutz, R. J. (1977) "Effects of interactive imagery on learning: Application to advertising", Journal of Applied Psychology, 62(4), 493-498.

[12] McCurry, Justin (2016), "The inventor of emoji on his famous creations-and his all-time favorite" retrieved from https://www.theguardian.com/technology/2016/oct/27/em oji-inventor-shigetaka-kurita-moma-new-york-text

[13] Mitchell,A.A.(1986) "The effect of verbal and visual components of advertisements on brand attitudes and attitude toward the Ads", Journal of Consumer Research, 13,12-24.

[14] Petrov, Daniel (2018), "Watch Tim Cook try Animoji for Duke commencement ceremony" retrieved from https://www.phonearena.com/news/Watch-Tim-Cook-tryAnimoji-for-a-Duke-commencement-ceremony_id101811

[15] Rand, Ayn (1952) "Fountainhead", Published in India by Signet (1996 edition)

[16] Robb, Alice (2014), "How Using Emoji Makes Us Less Emotional" retrieved from https://newrepublic.com /article/118562/emoticons-effect-way-we-communicatelinguists-study-effects

[17] Shepard R N, 1967, "Recognition memory for words, sentences and pictures" Journal of Verbal Learning and Verbal Behaviour.Pg.156 -163

[18] Silvia et al. (2015), “Online Disinhibition Precursors and Outcomes” Journal of Media Psychology Oct 2015, Vol. 27, Issue 4, pp. 170-177

[19] Suler, J. (2004) "The online disinhibition effect" Cyberpsychology, Behavior and Social Networking, 2004 Jun;7(3):321-6.

[20] "Word of the Year 2015" retrieved from https:// en.oxforddictionaries.com/word-of-the-year/word-of-theyear-2015 